\section{MitraClip Therapy for Healed Infective Endocarditis - How Long Should We Wait After Active Infection? -}

Yuta Kato, MD; Makoto Amaki, MD; Hideaki Kanzaki, MD; Yu Kataoka, MD; Atsushi Okada, MD; Koji Miyamoto, MD; Yasuhiro Hamatani, MD; Masashi Amano, MD; Hiroyuki Takahama, MD; Takuya Hasegawa, MD; Yorihiko Matsumoto, MD; Tomoyuki Fujita, MD; Junjiro Kobayashi, MD; Hatsue Ishibashi-Ueda, MD; Satoshi Yasuda, MD; Chisato Izumi, MD

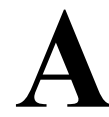
n 81-year-old man was admitted for heart failure with severe mitral regurgitation (MR). He had a history of infective endocarditis (IE; Figure A) successfully treated 3 months earlier. No signs of infection nor vegetation were observed (Figure B). Despite surgical mitral valve replacement (MVR) recommendation, he selected MitraClip ${ }^{\circledR}$ (Abbott Vascular, IL, USA). Two clips were carefully deployed, resulting in MR reduction to mild (Figure C, Supplementary Movie). One week later, symptoms worsened and the medial clip was found to be detached from the posterior leaflet, resulting in severe MR (Figure D). After surgical MVR, pathology indicated a scar due to the previous IE (Figure E,F). Additional to valve tethering and annulus dilatation, we identified the cause of detachment was due to valve vulnerability and valve tension created after MitraClip deployment.

Chandrashekar et al reported a case of MR successfully treated by MitraClip 1 month after acute IE, ${ }^{1}$ although the optimal timing after IE is controversial. The present findings of pathological valve vulnerability observed even 3 months after IE suggest that there is a risk of leaflet detachment after MitraClip deployment.

Received June 17, 2019; revised manuscript received July 27, 2019; accepted August 19, 2019; J-STAGE Advance Publication released online October 10, 2019 Time for primary review: 31 days

Department of Cardiovascular Medicine (Y. Kato, M. Amaki, H.K., Y. Kataoka, A.O., K.M., Y.H., M. Amano, H.T., T.H., S.Y., C.I.), Department of Cardiovascular Surgery (Y.M., T.F., J.K.), Department of Pathology (H.I.-U.), National Cerebral and Cardiovascular Center, Suita, Japan

Mailing address: Makoto Amaki, MD, Department of Cardiovascular Medicine, National Cerebral and Cardiovascular Center, 6-1 Kishibeshinmachi, Suita 564-8565, Japan. E-mail: amaki@ncvc.go.jp

ISSN-1346-9843 All rights are reserved to the Japanese Circulation Society. For permissions, please e-mail: cj@j-circ.or.jp

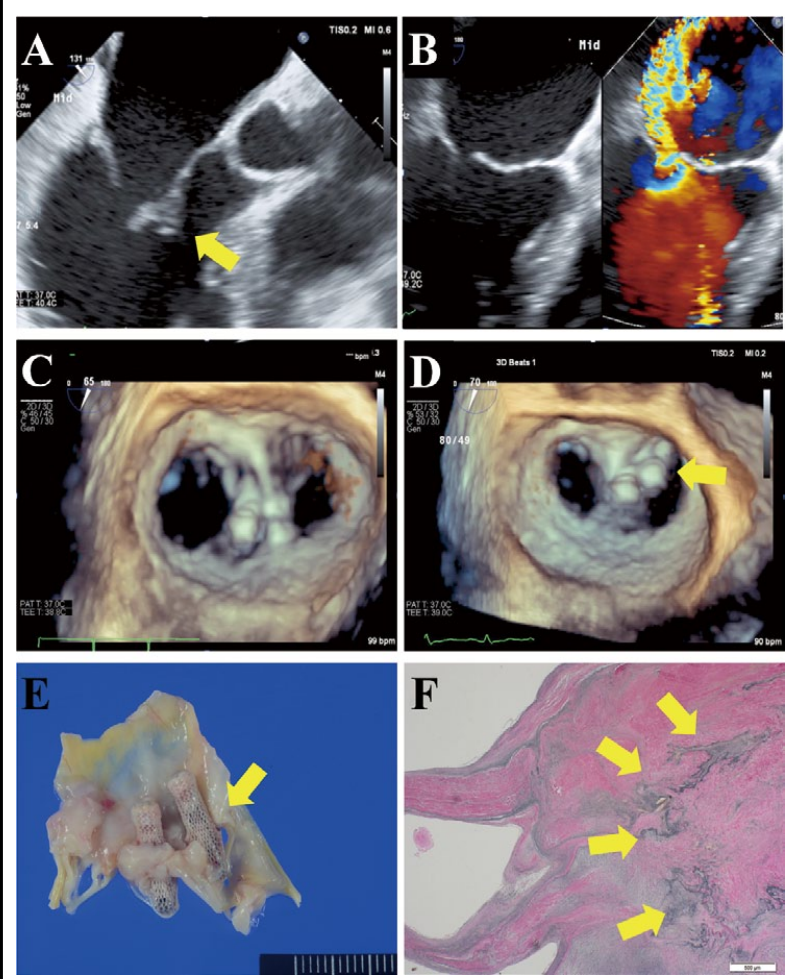

Figure. (A,B) Transesophageal echocardiography (TEE) showing $(\mathbf{A})$ vegetation (arrow) on the anterior leaflet in the acute phase of infective endocarditis and (B) severe mitral regurgitation due to shortening of the anterior leaflet at 3 months. (C,D) 3D-TEE (C) immediately after and (D) 1 week after MitraClip deployment (arrow). (E) Excised leaflet and detached clip (arrow). (F) Fibrous scar with elastic fiber disruption and neovascularization (arrow) of the leaflet on Elastica van Gieson stain.

\section{Disclosures}

The authors declare no conflicts of interest.

\section{Reference}

1. Chandrashekar P, Fender EA, Al-Hijji MA, Chandrasekaran K, Rihal CS, Eleid MF, et al. Novel use of MitraClip for severe mitral regurgitation due to infective endocarditis. $J$ Invasive Cardiol 2017; 29: E21-E22.

\section{Supplementary Files}

Supplementary Movie. Transesophageal echocardiography showing reduction in mitral regurgitation to mild, after deployment of 2 clips.

Please find supplementary file(s);

http://dx.doi.org/10.1253/circj.CJ-19-0523 